\title{
New Application of Chamaerops Humilis L. Extract as a Green Corrosion Inhibitor for Reinforcement Steel in a Simulated Carbonated Concrete Pore Solution
}

\author{
D. Benmessaoud Left ${ }^{a, *}$, M. Zertoubi ${ }^{a}$, S. Khoudali ${ }^{b}$ and M. Azzi ${ }^{a}$ \\ ${ }^{a}$ Laboratoire Interface Matériaux, Environnement (LIME), Faculté des Sciences, Université \\ Hassan II Casablanca, Morocco \\ ${ }^{b}$ Laboratoire de Synthèse Organique, Extraction et Valorisation (LSOEV), Faculté des \\ Sciences, Université Hassan II Casablanca, Morocco
}

Received March 15, 2017; accepted November 28, 2017

\begin{abstract}
In the present work, we present the first study about the effect of Chamaerops humilis $L$. extract on the behavior of reinforcement steel in a carbonated concrete pore solution $(\mathrm{pH} \approx 9)$. This study has been realized using electrochemical measurements: open circuit potential (OCP) and electrochemical impedance spectroscopy (EIS). The phytochemical screening was used to reveal the presence of some phyto-constituents in the plant extract. The Folin-Ciocalteu method and the $\mathrm{AlCl}_{3}$ coloration were used to determine the total phenolic and flavonoid contents, respectively. Results show that the plant extract has a beneficial effect on the development of a passive layer. The extract plays an important role in the corrosion potential evolution, and in the polarization resistance increase. The inhibition efficiency of the plant extract is close to $60 \%$ at a concentration of $0.75 \mathrm{~g} / \mathrm{L}$. Corrosion parameters also changed with exposure time.
\end{abstract}

Keywords: Reinforcement steel; carbonated concrete; pore solution; inhibitor; Chamaerops humilis L., and plant extract.

\section{Introduction}

Reinforcement steel corrosion in concrete has received considerable attention from academics and practical engineers. It has been identified as the primary cause of deterioration in concrete structures [1-2]. Under normal conditions, reinforcement steel is protected by the formation of a passive film mainly composed of $\mathrm{Fe}(\mathrm{II}) / \mathrm{Fe}$ (III) oxides, due to the high alkalinity of the concrete pore solution ( $\mathrm{pH}$ around 13) [3]. However, the passivity breakdown becomes easy when the chloride ions reach a threshold value in the pore solution, and/or the $\mathrm{pH}$ of the pore solution drops from its normal values to values approaching neutrality ( $\mathrm{pH}$ around 9), due to the carbonation of concrete [4-5].

\footnotetext{
* Corresponding author. E-mail address: benmessaoudleftdriss@gmail.com
} 
Various methods of protection and repair currently exist. One of the methods of combating corrosion is the use of corrosion inhibitors, which decrease the corrosion rates to the desired level, with minimal environmental impact. Harmful or toxic admixtures used in the construction industry have to be replaced, due to strict environmental protection regulations [6 and 7].

Environmental concerns have led researchers to value plant extracts containing various phytochemical compounds in industrial applications, to replace some inhibitors classified as toxic and unfriendly. Plant extracts have been widely used as green corrosion inhibitors, because they are considered as nontoxic, biodegradable, a rich source of organic molecules, and cost-effective [8-9]. In practical terms, the application of these natural products [10-12] is still insufficient.

In this work, to provide more information, the behavior of reinforcement steel has been studied in a simulated carbonated concrete pore solution in the presence of the methanolic extract of Chamaerops humilis L. (Arecaceae family) leaves. The phytochemical screening revealed the presence of some phyto-constituents in the plant extract, and the electrochemical measurements were used to understand the behavior of the reinforcement steel in the extract molecules presence.

\section{Experimental}

\section{Preparation of the plant extract}

Chamaerops humilis L. (CHL) plant was collected in the region of Essaouira, Morocco. The plant leaves were cut into small pieces and air-dried for ten days in the laboratory at room temperature. The extraction was realized by the Soxhlet technique during six hours, with methanol as solvent. The extracted solution was filtered, and the solvent was evaporated until reaching the solid phase. The solid phase was kept at $4{ }^{\circ} \mathrm{C}$. To study the corrosion inhibition properties, the methanolic extract was used at different concentrations ranging from $0.25 \mathrm{~g} / \mathrm{L}$ to $1 \mathrm{~g} / \mathrm{L}$. The extraction yield of the methanolic extract was $13 \%$.

\section{Phytochemical screening}

Phytochemical screening was done using standard procedures, as described in literature [13-14]. Samples of the leaves methanolic extract of (CHL) were screened for the following phyto-constituents: saponins, terpenoids, flavonoids, tannins and steroids.

\section{Determination of total phenolic contents}

The total phenolic content was determined according to the Folin-Ciocalteu colorimetric method [15]. The sample $(0.5 \mathrm{~mL})$, and $2 \mathrm{~mL}$ of a sodium carbonate solution $(75 \mathrm{~g} / \mathrm{L})$ were added to $2.5 \mathrm{~mL}$ of $10 \%$ of the Folin-Ciocalteu reagent. After $30 \mathrm{~min}$ of reaction at room temperature, the absorbance was measured at $765 \mathrm{~nm}$. Gallic acid was used as standard for the calibration curve. The results are expressed in $\mathrm{mg}$ gallic acid equivalents per gram extract (mg GAE/g extract). All determinations were performed in triplicate. 


\section{Determination of total flavonoid contents}

The content of this group of compounds was quantified as described elsewhere [16]. To $0.5 \mathrm{~mL}$ of the sample or standard, it was added $0.5 \mathrm{~mL}$ of the $2 \% \mathrm{AlCl}_{3}$ ethanol solution. After $10 \mathrm{~min}$ at room temperature, the absorbance was measured at $420 \mathrm{~nm}$. Quercetin was used as a standard for plotting the calibration curve, and the results are expressed in $\mathrm{mg}$ quercetin equivalents per gram extract (mg QuE/g extract). Samples were analyzed in triplicate.

\section{Sample and solution preparation}

The FeE500 reinforcement steel with the chemical composition showed in Table 1 was used as working electrode. The electrode was axially embedded in Teflon, leaving a surface area of $0.158 \mathrm{~cm}^{2}$. Before each electrochemical experiment, the exposed area was mechanically polished with 400, 800, 1200 and 1500 grades of abrasive papers, rinsed with demineralized water, and degreased with acetone. The testing solution was composed of $\mathrm{K}_{2} \mathrm{CO}_{3}\left(0.125 \mathrm{M}, \mathrm{KHCO}_{3}(0.25 \mathrm{M})\right.$, $\mathrm{Na}_{2} \mathrm{CO}_{3}(0.025 \mathrm{M})$ and $\mathrm{NaHCO}_{3}(0.05 \mathrm{M})$, simulating the carbonated concrete pore solution (CCPS). The $\mathrm{pH}$ value was around 9. The solution was prepared using grade chemical reagents and demineralized water.

Table 1. Chemical composition of the reinforcement steel.

\begin{tabular}{ccccccccccccc}
\hline $\mathbf{C}$ & $\mathbf{P}$ & $\mathbf{S}$ & $\mathbf{N}_{\mathbf{2}}$ & $\mathbf{M n}$ & $\mathbf{C r}$ & $\mathbf{N i}$ & $\mathbf{C u}$ & $\mathbf{S n}$ & $\mathbf{M o}$ & $\mathbf{V}$ & $\mathbf{S i}$ & $\mathbf{F e}$ \\
\hline 0.22 & 0.05 & 0.05 & 0.012 & 0.80 & 0.3 & 0.3 & 0.5 & 0.05 & 0.05 & 0.08 & 0.3 & balance \\
\hline
\end{tabular}

\section{Electrochemical measurements}

Electrochemical measurements, including open circuit potential and electrochemical impedance spectroscopy, were performed in a three-electrode cell. The reinforcement steel was used as working electrode, platinum as counter electrode, and a saturated $\mathrm{Ag} / \mathrm{AgCl}$ as reference electrode. The open circuit potential curves were recorded during four hours in CCPS, with and without the extract. Electrochemical impedance spectroscopy measurements were carried out at different immersion times using $\mathrm{AC}$ signals of $10 \mathrm{mV}$ of amplitude in the frequency range of $100 \mathrm{KHz}$ to $10 \mathrm{mHz}$, with data density of 10 points per decade. Electrochemical experiments were performed with a 40 PGZ 301 potentiostat/galvanostat voltalab model (analytical radiometer), monitored by voltamaster 4 software. The electrode rotation rate was fixed at $1000 \mathrm{rpm}$. Each experiment was repeated three times to confirm the reproducibility of the results at $22 \pm 1{ }^{\circ} \mathrm{C}$, and in an aerated solution.

\section{Results and discussion \\ Phytochemical analysis}

The phytochemical tests were employed to qualify the different chemical families present in the extracts [17]. The tests realized on the methanolic extract of CHL leaves confirmed the presence of flavonoids, tannins, saponins, terpenoids, and the absence of steroids. The same results were obtained with the 
methanolic extract of Algeria (Tlemcen area) and Morocco (Benslimane area) CHL [18-19]. The plant extracts showed a good inhibition action in acidic and alkaline environments, measured by different electrochemical methods [20-21]. No studies related to the anticorrosion properties of this plant extracts in carbonated concrete pore solutions were found in literature.

\section{Phenolic and flavonoid contents}

In the present study, we applied the Folin-Ciocalteu method and the $\mathrm{AlCl}_{3}$ coloration to determine the total phenolic and flavonoid contents of the methanolic extract of CHL leaves. The total phenolic content was $125.847 \pm 0.378$ $\mathrm{mg}$ gallic acid equivalent GAE/g extract, while the flavonoid content was $2.663 \pm 0.244 \mathrm{mg} \mathrm{QuE} / \mathrm{g}$ extract.

According to the showed results, the presence of these phyto-constituents indicates several organic compounds of high molecular weight with heteroatoms in their chemical structures. The majority of organic compounds containing heteroatoms such as $\mathrm{O}, \mathrm{N}$ or $\mathrm{S}$, and multiple bonds, allows an adsorption onto the metal surface [22-23]. To evaluate the effect of the CHL extract, electrochemical measurements have been realized using open circuit potential (OCP) and electrochemical impedance spectroscopy (EIS) techniques.

\section{Electrochemical measurements}

Fig. 1 illustrates the evolution with time of the open circuit potential, $E_{\text {corr, }}$ of reinforcement steel without and with different concentrations of the extract, after 4 hours immersion.

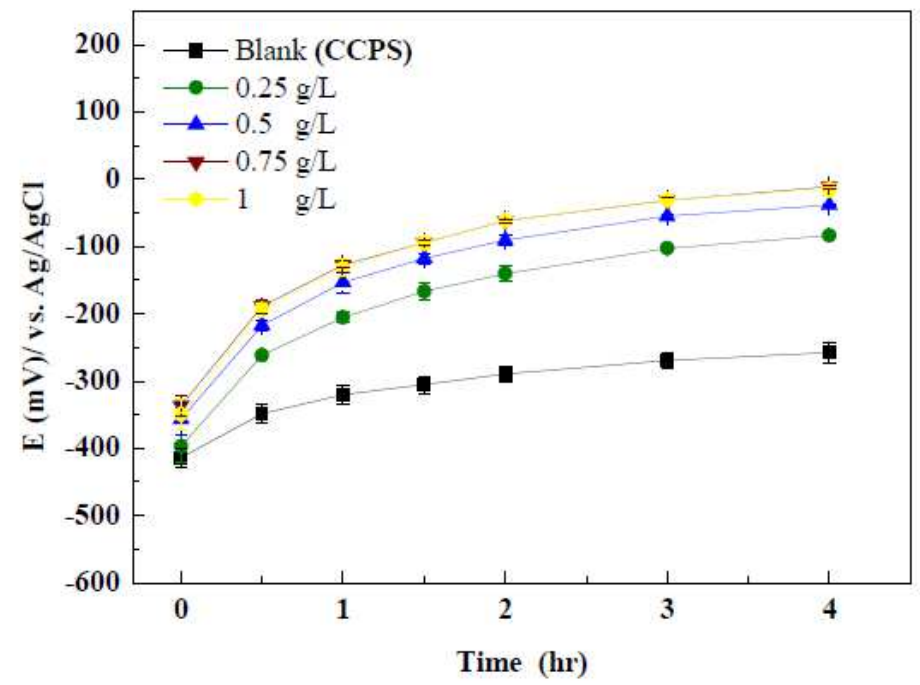

Figure 1. Evolution of the potential, with immersion time, of reinforcement steel in a simulated carbonated concrete pore solution, without and with different concentrations of CHL leaves methanolic extract.

In all cases, the shape of the curves is similar. During the first 2 hours of immersion, $E_{\text {corr }}$ significantly increased with time, and then progressively stabilized. The shift of the corrosion potential in the anodic potential direction can be attributed to the formation of an oxide film [24]. Thickening of the film 
continues until passivity is reached [25]. Without the extract this process is rather slow, but in the presence of different concentrations of the extract it is much more rapid. The potential value is more positive, indicating more passivation [26]. In the extract presence, the electrode potential increases about $\approx 200 \mathrm{mV}$, compared to the case without extract, after 4 hours of immersion. This finding can be explained by the contribution of the extract molecules to the development of the passive layer. A similar result was observed by adding nitrite ions, especially in the first hours of immersion; this indicated that ions promote and accelerate the passivation of steel in a carbonated solution [24].
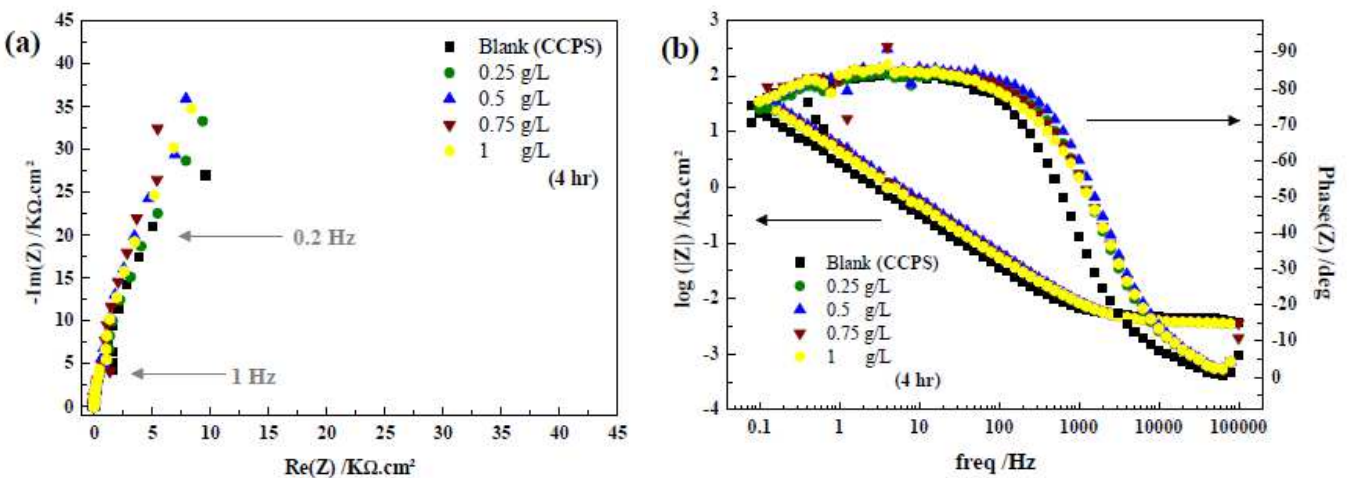

Figure 2. Nyquist (a) and Bode (b) plots of reinforcement steel in a carbonated concrete pore solution, without and with different extract concentrations.

Electrochemical impedance spectroscopy is a well-established and powerful technique in the study of corrosion. The protection efficiency results from the metal and alloys surface films in various environments. Electrode kinetics and mechanistic information can be obtained from the impedance studies $[8,26,27]$. In this work, this technique has been used to study the behavior of reinforcement steel in a carbonated concrete pore solution in the plant extract presence. Fig. 2 (a) and (b) show the Nyquist and Bode plots obtained at the open circuit potential after 4 hours of immersion. The curves evolution is similar for all the samples, which indicates that no change in the corrosion mechanism occurs as a result of the inhibitor addition [8 and 28]. One capacitive loop is observed on the Nyquist representation, which means that the phenomena occurred at the same rate. This is in accord with the observation of the Bode representation. Independently of the extract concentration, the Bode plots are characterized by one time constant represented by a large peak. The same behavior was obtained by Chen-Quing Ye et al. [29]. This large peak may also indicate the presence of two phenomena which have overlapped, or have very close time constants.

Authors have frequently used equivalent electrical circuits to obtain the parameters associated with the impedance diagrams for the corrosion of reinforcement steel [29-32]. Constant phase element (CPE) is used instead of a capacitance to assess the non-ideal behavior of the metal/solution interface. The $\mathrm{CPE}$ is given by:

$$
\mathrm{Z}_{\mathrm{CPE}}=\frac{1}{Q(j u)^{\alpha}}
$$


where $\alpha$ is related to the rotation angle of a purely capacitive line on the complex plane plots, and $\mathrm{Q}$ is a constant expressed in $\left(\Omega^{-1} \mathrm{~cm}^{-2} \mathrm{~s}^{\alpha}\right)$ or $\left(\mathrm{F} \mathrm{cm}^{-2} \mathrm{~s}^{(\alpha-1)}\right)[33$ and 34]. In the present study, the parameters were graphically obtained. The solution resistance (Rs) and the resistance associated to the capacitive loop ( $R p)$, physically related to the corrosion resistance, were directly measured on the impedance spectra [33]. The inhibition efficiencies (IE) are calculated by the following equation:

$$
\operatorname{IE}(\%)=\left[\left(R_{P}-R_{p}^{0}\right) / R_{P}\right] \times 100
$$

where $\mathrm{R}_{\mathrm{P}}^{0}$ and $\mathrm{R}_{\mathrm{P}}$ are, respectively, the polarization resistance associated to the capacitive loop, without and with the plant extract.

Then, the parameters $\alpha$ and $\mathrm{Q}$ were determined using the graphical methods presented by Orazem et al., and Musiani et al. [35 and 36]. The $\alpha$ CPE parameter was determined by the following formula, according to Hirschorn et al. [37]:

$$
\alpha=\left|\frac{\operatorname{dog}|z i|}{\operatorname{dlog} f}\right|
$$

The Q CPE parameter was obtained by the following equation [35]:

$$
Q_{e f f}=\sin \left(\frac{\alpha \pi}{2}\right)\left(\frac{-1}{z^{n}(2 \pi f)^{\alpha}}\right)
$$

The plot of $\alpha$ and Q CPE parameters was presented in Fig. 3 (a) and (b).

$$
\mathrm{C}_{e f f}=\left(Q \times R_{p}^{1-\alpha}\right)^{1 / \alpha}
$$
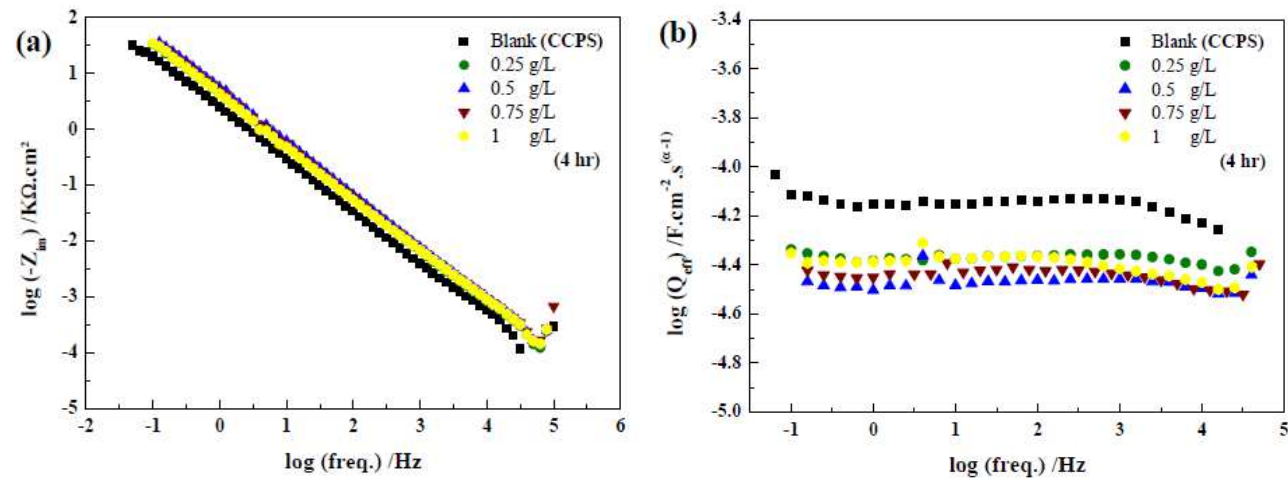

Figure 3. $\alpha$ CPE parameters (imaginary part of the impedance as a function of frequency / logarithmic scale). (a) Effective Q CPE parameters defined by Eq. (4) and, (b), of reinforcement steel in a carbonated concrete pore solution, without and with different concentrations of the extract.

These parameters calculated for both uninhibited and inhibited solutions are summarized in Table 2. The effective capacitance, $\mathrm{C}_{\text {eff }}$,(expressed in Faradays), was calculated from the CPE parameters using the Hsu and Mansfeld formula [38]. Many authors used this formula for the studied passive film [39 and 40] and corrosion inhibitors [17 and 41]. 
From Table 2, it is clear that the extract addition increases the polarization resistance ( $\mathrm{Rp}$ ) and decreases the effective capacitance. Consequently, the corrosion inhibition efficiency calculated from Eq. 2 increases with time in the presence of different extract concentrations. The decrease in the Q CPE parameter and in the effective capacitance $\left(\mathrm{C}_{\mathrm{eff}}\right)$ with the extract addition confirms the formation of a protective adsorption layer onto the reinforcement steel surface, and the increase in the corrosion inhibition [8 and 17]. Also, $\alpha$ CPE parameter value close to 0.9 can be related to a capacitive response, typical of a protective passive layer [42]. Therefore, these results suggest, once again, that this extract participates in the formation of the passive film with an improvement in its polarization resistance. The Rp values increased from 124 to $302 \mathrm{~K} \Omega . \mathrm{cm}^{2}$, after 4 hours of immersion, to record a maximum corrosion inhibition efficiency of $\approx 60 \%$ for $0.75 \mathrm{~g} / \mathrm{L}$ of the plant extract.

Table 2. Values obtained from the EIS data of reinforcement steel in a carbonated concrete pore solution without and with different extract concentrations.

\begin{tabular}{|c|c|c|c|c|c|c|}
\hline \multirow{2}{*}{$\begin{array}{l}\text { CCPS } \\
\text { parameters }\end{array}$} & \multirow{2}{*}{$\begin{array}{l}\text { Immersion } \\
\text { time }\end{array}$} & \multirow[b]{2}{*}{ Blank } & \multicolumn{4}{|c|}{ Extract concentrations $(\mathrm{g} / \mathrm{L})$} \\
\hline & & & 0.25 & 0.5 & 0.75 & 1 \\
\hline $\operatorname{Rs}\left(\Omega . \mathrm{cm}^{2}\right)$ & & $5.24 \pm 0.77$ & $3.71 \pm 0.07$ & $3.70 \pm 0.02$ & $3.71 \pm 0.08$ & $3.69 \pm 0.01$ \\
\hline $\mathrm{Rp}\left(\mathrm{k} \Omega \cdot \mathrm{cm}^{2}\right)$ & & $99 \pm 5$ & $111 \pm 3$ & $143 \pm 3$ & $153 \pm 4$ & $148 \pm 2$ \\
\hline Q. $10^{-6}\left(\mathrm{~F}^{-\mathrm{cm}^{-2} \cdot \mathrm{s}}{ }^{(\alpha-1)}\right)$ & $2 \mathrm{hr}$ & $84 \pm 4$ & $50 \pm 1$ & $42 \pm 3$ & $40 \pm 1$ & $49 \pm 3$ \\
\hline$\alpha$ & & $0.92 \pm 0.01$ & $0.93 \pm 0.00$ & $0.93 \pm 0.01$ & $0.94 \pm 0.00$ & $0.93 \pm 0.01$ \\
\hline$C_{\text {eff }}\left(\mu \mathrm{F} \cdot \mathrm{cm}^{-2}\right)$ & & $100 \pm 5$ & $57 \pm 1$ & $48 \pm 3$ & $46 \pm 1$ & $58 \pm 5$ \\
\hline IE \% & & - & 11 & 31 & 35 & 33 \\
\hline $\operatorname{Rs}\left(\Omega . \mathrm{cm}^{2}\right)$ & & $5.94 \pm 0.42$ & $3.64 \pm 0.02$ & $3.65 \pm 0.04$ & $3.79 \pm 0.04$ & $3.69 \pm 0.02$ \\
\hline $\mathrm{Rp}\left(\mathrm{k} \Omega \cdot \mathrm{cm}^{2}\right)$ & & $127 \pm 12$ & $161 \pm 4$ & $194 \pm 4$ & $209 \pm 7$ & $207 \pm 2$ \\
\hline Q. $10^{-6}\left(\mathrm{~F} \mathrm{~cm}^{-2} \cdot \mathrm{s}^{(\alpha-1)}\right)$ & $3 \mathrm{hr}$ & $75 \pm 1$ & $48 \pm 3$ & $37 \pm 4$ & $38 \pm 1$ & $44 \pm 1$ \\
\hline$\alpha$ & & $0.93 \pm 0.01$ & $0.93 \pm 0.01$ & $0.94 \pm 0.01$ & $0.94 \pm 0.00$ & $0.93 \pm 0.00$ \\
\hline $\mathrm{C}_{\text {eff }}\left(\mu \mathrm{F} \cdot \mathrm{cm}^{-2}\right)$ & & $88 \pm 3$ & $56 \pm 4$ & $42 \pm 5$ & $43 \pm 1$ & $52 \pm 1$ \\
\hline IE \% & & - & 21 & 35 & 39 & 39 \\
\hline $\operatorname{Rs}\left(\Omega . \mathrm{cm}^{2}\right)$ & & $5.6 \pm 0.8$ & $3.69 \pm 0.01$ & $3.65 \pm 0.01$ & $3.87 \pm 0.03$ & $3.74 \pm 0.00$ \\
\hline $\mathrm{Rp}\left(\mathrm{k} \Omega . \mathrm{cm}^{2}\right)$ & & $124 \pm 10$ & $174 \pm 1$ & $235 \pm 4$ & $302 \pm 2$ & $271 \pm 1$ \\
\hline 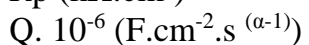 & $4 \mathrm{hr}$ & $71 \pm 2$ & $46 \pm 4$ & $34 \pm 1$ & $36 \pm 1$ & $42 \pm 1$ \\
\hline$\alpha$ & & $0.93 \pm 0.00$ & $0.93 \pm 0.01$ & $0.94 \pm 0.01$ & $0.94 \pm 0.00$ & $0.94 \pm 0.01$ \\
\hline $\mathrm{C}_{\mathrm{eff}}\left(\mu \mathrm{F} \cdot \mathrm{cm}^{-2}\right)$ & & $83 \pm 3$ & $54 \pm 5$ & $38 \pm 2$ & $42 \pm 1$ & $50 \pm 1$ \\
\hline IE \% & & - & 29 & 47 & 59 & 54 \\
\hline
\end{tabular}

\section{Effect of exposure time}

The immersion time also plays an important role in the formation of the passive film without and with the extract. We notice an increase in $\mathrm{Rp}$ and a decrease in $\mathrm{Q}$ and $\mathrm{C}_{\text {eff. }}$ This allows us to say that the immersion time promotes the formation and growth of a compact passive film. Considering that the carbonate and bicarbonate ions have an inhibitory effect against pitting corrosion [43], it is possible that a synergy effect is established between these ions and the extract molecules adsorbed onto the reinforcement steel surface. This may explain the evolution of open circuit potential to more positive values with immersion time, in the extract presence, and confirm their contribution to the enhancement of the passive film protection. 


\section{Conclusion}

Based on the obtained data and above analysis, the following conclusions are drawn:

- The methanolic extract of (CHL) is viewed as an incredibly rich source of naturally synthesized chemical compounds.

- The extract showed a beneficial effect, and it has improved the resistance of a passive film formed on the steel surface.

-The optimal corrosion inhibition efficiency of the extract is $\approx 60 \%$ for $0.75 \mathrm{~g} / \mathrm{L}$.

- The extract improves the electrochemical parameters by ennobling the corrosion potential and increasing the polarization resistance. It may be considered as a good inhibitor for reinforcement steel in a carbonated concrete pore solution.

\section{References}

1. Zhao Y, Jin W. Steel Corrosion-Induced Concrete Cracking. $1^{\text {st }}$ ed. Heinemann: Butterworth; 2016.

2. El-Reedy MA. Steel-Reinforced Concrete Structures. Taylor \& Francis Group; 2008.

3. Ghods P, Isgor OB, Bensebaa F, et al. Corros Sci. 2012;58:159-167.

4. Bertolini L. Struct Infrastruct Eng. 2008;4:123-137.

5. Bertolini L, Elsener B, Pedeferri P, et al. Corrosion of steel in concrete: Prevention, Diagnosis, Repair. Weinheim: Wiley-VCH; 2013.

6. Sastri VS. Green corrosion inhibitors: Theory and Practice, New Jersy: John Wiley \& Sons; 2011.

7. Elsener B. Corrosion Inhibitors for Steel in Concrete: State of the Art Report. European Federation of Corrosion: Maney Publishing; 2001.

8. Faustin M, Maciuk A, Salvin P, et al. Corros Sci. 2015;92:287-300.

9. Raja PB, Sethuraman MG. Mater Lett. 2008;62:113-116.

10. Asipita SA, Ismail M, Majid MZA, et al. J Clean Prod. 2014;67:139-146.

11. Okeniyi JO, Omotosho OA, Ogunlana OO, et al. Energy Procedia. 2015;74:1274-1281.

12. Okeniyi JO, Loto CA, Popoola API. Energy Procedia. 2014;50:429-436.

13. Shah BN, Seth AK. Textbook of Pharmacognosy and Phytochemistry. $1^{\text {st }}$ ed. India: Elsevier; 2010.

14. Evans WC. Trease and Evans Pharmacognosy. $15^{\text {th }}$ ed. Edinburgh: WB Saunders Co Ltd; 2002.

15. Singleton VL, Rossi JA. Am J Enol Vitic. 1965;16:144-158.

16. Ahn M, Kumazawa S, Usui Y, et al. Food Chem. 2007;101:1383-1392.

17. Suedile F, Robert F, Roos C, et al. Electrochim Acta. 2014;133:631-638.

18. Benmehdi H, Hasnaoui O, Benali O, et al. J Mater Environ Sci. 2012;3:320327.

19. Khoudali S, Left DB, Essaqui A, et al. J Mater Environ Sci. 2014;5:887-898.

20. Benali O, Benmehdi H, Hasnaoui O, et al. J Mater Environ Sci. 2013;4:127138. 
21. Left DB, Zertoubi M, Khoudali $S$, et al. Int $J$ Electrochem Sci. 2013;8:11768-11781.

22. Ormellese M, Lazzari L, Goidanich S, et al. Corros Sci. 2009;51:2959-2968.

23. Abiola OK, Tobun Y. Chin Chem Lett. 2010;21:1449-1452.

24. Reffass M, Sabot R, Jeannin M, et al. Electrochim Acta. 2007;52:7599-7606.

25. Abd El Haleem SM, Abd El Wanees S, Abd El Aal EE, et al. Corros Sci. 2010;52:292-302.

26. Metikoš-Huković M, Škugor I, Grubač Z, et al. Electrochim Acta. 2010;55:3123-3129.

27. Lorenz WJ, Mansfeld F. Corros Sci. 1981;21:647-672.

28. Reis FM, De Melo HG, Costa I. Electrochim Acta. 2006;51:1780-1788.

29. Ye CQ, Hu RG, Dong SG, et al. J Electroanal Chem. 2013;688:275-281.

30. Ai Z, Jiang J, Sun W, et al. Appl Surf Sci. 2016;389:1126-1136.

31. Liu G, Zhang Y, Ni Z, et al. Constr Build Mater. 2016;115:1-5.

32. Shi J, Sun W, Jiang J, et al. Constr Build Mater. 2016;111:805-813.

33. Ochoa N, Vega C, Pébère N, et al. Mater Chem Phys. 2015;156:198-205.

34. Zoltowski P. J Electroanal Chem. 1998;443:149-154.

35. Orazem ME, Pébère N, Tribollet B. J Electrochem Soc. 2006;153:B129B136.

36. Musiani M, Orazem M, Tribollet B, et al. Electrochim Acta. 2011;56:80148022.

37. Hirschorn B, Orazem ME, Tribollet B, et al. Electrochim Acta. 2010;55:6218-6227.

38. Hsu CH, Mansfeld F. Corrosion. 2001;57:747-748.

39. Jović VD, Jović BM. Corros Sci. 2008;50:3063-3069.

40. Mohammadi F, Nickchi T, Attar MM, et al. Electrochim Acta. 2011;56:8727-8733.

41. Bouanis M, Tourabi M, Nyassi A, et al. J Appl Surf Sci. 2016;389:952-966.

42. Yohai L, Schreiner W, Vázquez M, et al. Electrochim Acta. 2016;202:231242.

43. Tan YT, Wijesinghe SL, Blackwood DJ. Corros Sci. 2014;88:152-160. 